\title{
ALFABETIZAÇÕES NUMA PERSPECTIVA DISCURSIVA: SÓ O PLURAL PODE SER SINGULAR
}

\author{
LUDMILA THOMÉ DE ANDRADE'
}

\begin{abstract}
Resumo
Pesquisas sobre Alfabetização permitem defender a concepção discursiva da alfabetização, dentre tantas, por sua produtividade didática para o ensino e aprendizagem da língua escrita. Apresentamo-la, defendendo-a como já praticada por professores alfabetizadores, com quem temos debatido. A fundamentação teórica ancora-se nos estudos de Letramento, subsidiada por abordagens que se apoiam na Análise do Discurso de linha francesa, à qual acorrem ainda os textos de Mikhail Bakhtin e ideias de Lev Vigotski. Aproximamo-nos da perspectiva defendida a partir de três pontos: identidades dos atores envolvidos marcadas por alteridades; a configuração histórica na epistemologia do campo de formação de professores e a voz docente, por autores professores alfabetizadores, publicados.
\end{abstract}

Palavras-chave: Alfabetização; Concepção discursiva de linguagem; Práticas alfabetizadoras.

\section{READING LEARNING IN A DISCOURSIVE PERSPECTIVE: ONLY THE PLURAL CAN BE SINGULAR}

\begin{abstract}
The research on literacy in the Brazilian Education allows to defend the discursive conception of literacy. The theoretical conception worth to be highlighted, for its didactic productivity, with regard to written language in the early years of elementary school. We present it, defending it as already practiced by teachers with whom we have discussed in teacher training processes. The framework we developed is founded on studies of literacy, nourished by approaches that rely on the Discourse Analysis, which still is based on Mikhail Bakhtin texts and Lev Vygotsky's ideas. We approach the perspective from three points of view: identities of the actors involved;
\end{abstract}

1 Graduação em Letras pela Universidade Federal do Rio de Janeiro (UFRJ). Mestrado em Linguística Aplicada pela Universidade Estadual de Campinas (Unicamp). Diplôme d’études approfondies (DEA/mestrado) em Analyse du Discours na Université Paris III (Sorbonne-Nouvelle). Doutorado em Sciences de L'Education na Université de Paris VIII. Professora Titular de Formação de Professores da Faculdade de Educação da UFRJ. Pós-doutorado na Université Paris VIII, Pós-doutorado na Unicamp, no Instituto de Estudos da LinguagemAtua em Formação de Professores, principalmente nos temas formação continuada, análise do discurso, alfabetização, letramento, escrita e leitura e ensino de língua materna. 
its historic setting, in the epistemology of teacher training course and "teachers' voices", through teachers ' texts published, as authors.

Keywords: Literacy; Discursive Conceptions of language; Reading and writing teaching practices.

\section{ALFABETIZACIONES EN UNA PERSPECTIVA DISCURSIVA: SOLO EL PLURAL PUEDE SER SINGULAR}

Las investigaciones sobre Alfabetización permiten defender la concepción discursiva de la alfabetización, entre tantas, por su productividad didáctica para la enseñanza y el aprendizaje de la lengua escrita. La presentamos, defendiéndola como ya practicada por profesores alfabetizadores, con quienes hemos debatido. La fundamentación teórica se ancla en los estudios de Letramento, subsidiada por enfoques que se apoyan en el Análisis del Discurso de línea francesa, a la que acuden aún los textos de Mijaíl Bakhtin e ideas de Lev Vigotski. Nos acercamos a la perspectiva defendida a partir de tres puntos: identidades de los actores implicados marcados por alteridades; la configuración histórica en la epistemología del campo de formación de profesores y la voz docente, por autores profesores alfabetizadores, publicados.

Palabras clave: Alfabetización; Concepción discursiva de Lenguaje; Prácticas alfabetizadoras.

\section{Pesquisa em alfabetização: concepções de linguagem e educação}

A experiência das pesquisas sobre a alfabetização na Educação Básica brasileira permite hoje afirmar e defender a concepção discursiva da alfabetização. Trata-se de uma concepção teórica dentre tantas, mas ela antes de tudo vale ser destacada por sua produtividade didática, em termos de ensino e de aprendizagem, no que diz respeito à língua escrita nos anos iniciais do Ensino Fundamental.

Nesse artigo, apresentamos essa concepção, buscando defendê-la como possível, desejável e já praticada por professores alfabetizadores, com quem temos debatido. Nos diversos momentos atravessados como pesquisadora, ativemo-nos sempre a manter um olhar que foi gradualmente construído através de pesquisas de tipo pesquisa-ação, metodologia mais condizente com as concepções teóricas que defendemos. Na verdade, como a ação destas pesquisas configurava-se necessariamente como ações de formação de professores, as chamávamos, mais precisamente, de pesquisa-formação (ANDRADE, 2014a). Pesquisamos lado a lado e em constante escuta sintonizada com a voz docente - e como agiríamos diferentemente, se nossos objetivos de pesquisa ressaltavam a transformação do campo a 
ser analisado? Não nos contentávamos com pesquisas descritivas, sobre aspectos pontuais. Buscávamos argumentar que, para se defender uma posição a respeito de práticas educativas, caso se assuma um posicionamento ética e responsavelmente coerente, é imprescindível considerar da forma mais cuidadosa possível os principais interessados por estas conclusões, ou seja, os professores.

A fundamentação teórica que desenvolvemos ancora-se nos estudos de letramento (STREET, 2010; LILLIS, 2012 (informação verbal) ${ }^{2}$; MARINHO; CARVALHO, 2010) e é especialmente subsidiada por abordagens que se apoiam na Análise do Discurso de linha francesa, à qual acorrem ainda os textos de Mikhail Bakhtin e ideias de Lev Vigotski (CORREA, 2004; ABAURRE; FIAD; MAYRINK-SABINSON, 1997; ARENA, 2013; BORÉ; BOSREDON, 2013; DOQUET-LACOSTE, 2009; SMOLKA, 1988). As abordagens sobre os processos educacionais, situados num ponto de vista macro, remetem-se a Stephen Ball (2002) e fazem referência a Michel Foucault (1971), tendo em vista que consideramos recontextualizações, no sentido de Ball, desde um plano de ordem política, para chegar a poder finalmente considerar a voz docente e os textos dos profissionais professores como nossos dados.

Em coerência com esta fundamentação, aproximamo-nos da perspectiva a ser defendida a partir três pontos de vista: i) o das identidades dos atores envolvidos, marcadas pelas alteridades em jogo; ii) o da sua configuração histórica, tomando-se a epistemologia do campo de formação de professores da educação básica, e iii) a própria voz docente, através de textos de autores professores alfabetizadores, publicados. Identidades, história e atos por meio de escritas configuram nosso objeto de análise e estruturam as seções deste artigo. Ressalto a relevância do último ponto, o do ato de escrita docente e posterior publicação, pois somente se tomamos em conta os enunciados dos professores compreenderemos a realidade estudada. O professor traduz, redefine e consolida seus posicionamentos, com suas próprias palavras, com seu estilo.

\section{Sobre as identidades consteladas entre docentes, discentes e outros}

Pela concepção discursiva, as diferentes experiências, adulta, infantil, profissional e de outras identidades, dos diferentes sujeitos que se relacionam nas interações escolares, são constantemente alteradas, mutuamente intervenientes. É o que permite considerarmos a qualidade das interações, como interlocuções. Nem

2 Informação fornecida por Lellis em Oficina-palestra proferida na abertura do I Seminário Escrita Docente \& Discente https://sites.google.com/site/escritadocenteediscente/ 
toda interação é interlocução, a interlocução sendo um tipo de interação que se densifica pela linguagem verbal. A interlocução marca os sujeitos, a linguagem se marca nos seus atos de enunciação, os sujeitos são marcados pela linguagem assim apropriada, no tempo dos enunciados. A partir desta definição, pode-se compreender que um sujeito existe apenas marcado pelo olhar do outro, a quem se dirige, mesmo que tacitamente. A perspectiva discursiva encerra uma concepção alteritária de linguagem, de modo que não se pode tratar da "alfabetização dos alunos", sem se tratar de seus professores também, que estão com eles, constituindo-os, mediando os processos pedagógicos de apresentação da língua escrita.

Levamos às máximas consequências tal pressuposto da alteridade, em todos os níveis das relações, para além do nível micro, onde se passam as interações escolares, entre professores e seus alunos, considerando com a maior relevância o letramento do professor na sua relação com os agentes envolvidos em sua formação inicial e continuada. Neste sentido, encontramo-nos conosco, pois a universidade participa por diversas vias da formação do professor, constituindo as identidades docentes em termos de nossas ideias construídas pela pesquisa, defendidas em publicações e comunicadas e difundidas, desde a formação inicial até a formação continuada.

Nossa escolha teórica pelo discurso permite-nos pensar nas práticas sociais e de socialização dos professores sempre em relação com a dos alunos, práticas escolares docentes e discentes são mutuamente dependentes, articuladas, somente podem ser compreendidas contextualizadamente. De fato, se as práticas de letramento, ou seja, as ações que se fazem com a língua escrita, são o viés escolhido por nós para tratar do tema da alfabetização, seria improdutivo e estéril focalizar somente as práticas escolares de um dos agentes. Seria um equívoco focalizarmos os sujeitos isoladamente, em suas identidades e práticas, ou os seus textos produzidos por si mesmo. Professores ou alunos não podem ser vistos isoladamente em seu fazer linguístico, em sua relação com a linguagem produzida na escola.

A definição da constituição alteritária dos sujeitos incita-nos coerentemente a pensar nas interações de forma contextualizada, o que significa que o singular das interações que são sempre únicas torna-se plural e que o imponderável de cada enunciação pode ser analisado, embora e justamente porque seja sempre imprevisível. É neste sentido que definimos o singular de cada sujeito: através do plural das alteridades.

Por consequência, as práticas sociais de cada agente devem ser compreendidas em função das demais. As práticas de letramento profissional dos professores são consequência e efeito das práticas das crianças-alunos da escola, dos formado- 
res que estão em contato com eles em processos de formação, devendo ser também tomadas em consideração, bem como as das famílias, que constituem, por seus modos de socialização, a identidade infantil de suas crianças - que vão à escola e estão nas interações com os professores. Trata-se, assim, de uma constelação da qual se irradiam linhas cruzadas umas sobre as outras, interconstituindo os que usam a linguagem verbal, oral ou escrita, definidora de cada identidade.

Pesquisas sobre formação de professores têm abordado práticas sociais dos docentes e acabam tocando em seu letramento (BATISTA, 2007; UNESCO, 2004). As práticas sociais dos alunos, entretanto, são talvez mais raramente consideradas na literatura (THIN, 2006; SIROTA, 2001; COSTA, 2013) e talvez as pesquisas devessem se ocupar mais de compreender crianças que vão à escola, investigando tais práticas infantis. Apesar desta ausência da pesquisa, este saber é evidente no trabalho dos professores: cotidianamente, em sua atividade profissional, supõem, adivinham, aproximam-se, projetivamente, do que as crianças fazem no mundo, de suas práticas religiosas, literárias, esportivas etc., e observam também os modos das crianças de se relacionar com a língua escrita. É em função deste saber que passam a desenhar seus planejamentos, para suas práticas de ensino.

$\mathrm{Na}$ proposta aqui defendida, a chave está justamente em que professores estejam dispostos a analisar os textos infantis de seus alunos como formas de socialização escolar. Tais textos, produzidos em situações escolares de aquisição da língua escrita, são respostas que os alunos dão ao que é proposto pelo professor nas interações efetivamente realizadas. Podemos traduzir a proposta discursiva de alfabetização, portanto, pensando numa concepção de um professor leitor de textos discentes. Avaliar a qualidade dos textos infantis escolares, equivalerá, necessariamente, a avaliar seu próprio trabalho. Tanto mais "bem formado" será o professor que melhor souber discorrer consistentemente sobre estes textos, pois afinal seus alunos escrevem sob sua mediação. A medida da autoria docente, de um professor que reflete sobre o que faz, no exercício de seu trabalho, dá-se também por este tipo de desenvolvimento que possa realizar em termos reflexivos sobre a produção discente.

O professor vai ler/ver a produção discursiva de textos escritos de seus alunos como um resultado de seu próprio trabalho pedagógico. (Re)escrever suas decisões e planejamentos, para implementar espaços e tempos que permitirão aos escreventes aprendizes produzirem. Seus atos e seus textos sobre estes são sempre avaliações dos efeitos de seus atos sobre outros (discentes), uma resposta às respostas (ANDRADE, 2014b). 


\section{As ondas da alfabetização: por uma história epistemológica da alfabetização}

Insistimos sobre a abrangência do olhar da pesquisa em uma sua contextualização mais ampla, que tome tanto elementos macro, para se compreender mesos, quanto, finalmente, destaque exemplos enunciativos do micro, das interações, das palavras e expressões que comunicam, expressando através de detalhes o querer dizer dos sujeitos (MORTATI, 2007; BALL, 2002; ANDRADE, 2016).

A concepção discursiva de linguagem desafia os estudos teóricos sobre a língua, pela realidade empírica das formas de ensino da letra pelos praticantes experimentados, os professores. Tais profissionais, ao ensinarem, aprendem, porque produzem formas singulares de aprendizagem deste seu ensino, o que chamamos de apropriação (tornar próprio). São muitas as formas de se ensinar, mesmo que se siga a pauta prevista de uma sequência didática, as interações que decorrem das atividades docentes, se examinadas mais detidamente, nunca serão idênticas, variando de professor a professor, de aluno a aluno etc. Os professores não são idênticos a si mesmos, sua ação é muito variável, exercem seu fazer buscando, errando, ampliando os resultados conseguidos de ano para ano, num processo temporal que não se pode regularizar, homogeneizar, controlar com parâmetros externos, mas antes equacionar micro-contextualizadamente, pelos discursos em curso de sua formulação e produção, ou seja, em termos da teoria do discurso, enunciativamente (MAINGUENEAU, 1997; CORREA, 2004; BAKHTIN, 1988, 2002, 2003, 2013).

Os objetivos de nossa pesquisa sobre alfabetização incluem as mudanças a se operar no próprio campo estudado, pois o ato de pesquisar um objeto acarreta efeitos para o próprio objeto. Com o ato de escrita de pesquisas, os pesquisadores autores constróem realidades, criam representações que interferem na escola real, pois ao tomar contato com elas, os professores se miram, se auto-representam. $\mathrm{O}$ professor é destinatário, de uma pesquisa que é por si uma devolução, e é também um sujeito, que dela será leitor. O professor é personagem retratado pelo punho da pesquisa, herói das façanhas pedagógicas relatadas. Entretanto, não o é por sua própria escrita e autoria, mas pelas mãos do outrem escritor pesquisador, que o analisa, critica, faz dele o que bem entende.

Consideramos o professor como fundamental nesse processo teórico-científico que é necessariamente metodológico, tomando para nós a grande responsabilidade da universidade em trazer uma concepção teórica através dos seus investimentos, aprofundamentos e desenvolvimentos teóricos consistentemente 
sustentados pelo debate científico que tem uma ordem (do discurso) que o legitima e valida, especialmente no caso de pesquisas educacionais, que tem seu caráter intrinsecamente político (FOUCAULT, 1971).

A análise deste processo discursivo, para que seja assim considerado, não pode prescindir de pensá-lo historicamente. Em que momento da história das ideias sobre alfabetização ganha algum núcleo de sentido tal concepção discursiva?

Três Ondas em que se banharam os professores brasileiros, em maior ou menor escala, certamente se mesclam à concepção discursiva: construtivismo, letramento e método fônico ${ }^{3}$. A ideia metafórica das ondas tem sido sistematicamente apresentada em processos de formação continuada que coordenamos e tem se revelado muito bem recebida. Coaduna-se com a constituição identitária - neste caso um traço de identidade, epistemológica - dos professores, através da história de divulgação das ideias e de sua recepção por parte deles. Anteriormente ao boom do construtivismo dos anos 1980 (lá se vão 25 anos!), a querela dos métodos havia trazido muitas oscilações e uma grande pluralidade de formas de investimentos às escolas e aos professores. Materiais prontos, entrada didática pelo viés analítico do menor para o maior - ou sintético - seguindo a direção oposta, do maior para o menor. Com a revolução instaurada com os estudos de Emília Ferreiro, esta variedade de possibilidades se anulou, voltando-se todo o cenário de formação preponderante e hegemonicamente para esta nova teoria. Nos anos 1990, já bem adiantados os estudos de letramento, desembarcam no Brasil (em 1995, publica-se o livro de Angela Kleiman Os significados do Letramento e, em 1998, o de Magda Sorares, Letramento: um tema em três gêneros) (KLEIMAN, 1995; SOARES, 1998).

Por dentro destas ondas, em que momento e sob que circunstâncias se produz a abordagem que hoje é designada e reconhecida como uma perspectiva discursiva da alfabetização? Ela se apresenta em nosso meio, como veremos, com o livro de Ana Luiza Smolka (SMOLKA, 1988). Consolida-se, em função de apropriações feitas pelos professores, que amalgamam abordagens teóricas que se combinam, por suas mãos, pelas suas escolhas e ações profissionais.

Hoje ainda, a abordagem discursiva não é hegemônica, pois o construtivismo ferreireano, com sua formatação de base piagetiana, parece ganhar mais popularidade. A divulgação dos conhecimentos a partir de uma concepção de "língua como sistema" ganhou terreno (LUCIO, 2010, 2016) e a ideia de alfabetização como "apropriação do sistema da língua" foi incorporada intensivamente, desde o Pro-

3 Em 2010, no $1^{\circ}$ SIHELE, Seminário Internacional sobre História do Ensino de Leitura e Escrita: A constituição do campo da história da alfabetização no Brasil, nosso texto intitulado "O professor alfabetizador imantado entre propostas teóricas: o letramento e a metodologia do fônico" foi premiado, trazendo esta ideia de ondas da alfabetização. 
-Letramento $(\mathrm{PL})^{4}$, até o mais recente Pnaic ${ }^{5}$. O PL trazia em seu bojo uma visão mais complexa do que a apresentada pelo programa seu sucessor, pois amalgamava em seus volumes produzidos diversamente por diferentes centros de pesquisa de universidades diferentes, porém os materiais do Pnaic ativeram-se a uma só visão, estrita e enfaticamente defendida, que incorria nesta perspectiva construtivista.

A concepção discursiva da alfabetização está exemplarmente exposta na obra de Ana Luiza Smolka, resumida em seu livro A criança na fase inicial da Escrita - a alfabetização como processo discursivo. Nesta obra, datada em sua primeira edição de 1988 (há quase 30 anos), a autora apresenta uma pesquisa etnográfica, descrevendo momentos chave de sua entrada e permanência na escola como pesquisadora. Na obra, ela tece a crítica aos procedimentos didáticos instaurados, com os quais se depara, e propõe modos de fazer de acordo com princípios teóricos assumidos como colhidos primordialmente nos estudos bakhtinianos e vigotskianos, associados a autores da Análise de Discurso de linha francesa.

O construtivismo de Emilia Ferreiro (FERREIRO; TEBEROSKY, 1986) é objeto da crítica desta autora, destacando, para fazê-lo, a importância de uma ideia de sujeito-aluno, em sua relação com a linguagem. Ao professor alfabetizador caberia a responsabilidade de refletir e saber enunciar, com toda complexidade e riqueza, a sua concepção de criança, de aluno-criança, para poder conceber o seu trabalho cognitivo de forma singular.

O construtivismo trouxe, certamente, a elevação da importância de se compreender os movimentos cognitivos do sujeito ativo criança, aprendiz da língua escrita, descobrindo sua sistematicidade. Formulou diversas etapas deste desenvolvimento. Teve certamente por mérito revolucionário o fato de insistir da atividade do aprendiz, mais do que a do professor que ensina a língua. Inverteu a relação de ensino, focalizando-se no aprendiz e seus movimentos. Porém, o que se pode criticar nesse movimento é a concepção da língua e da linguagem verbal que ele encerra. Isto foi feito de maneira exemplar no estudo de Smolka, lido por professores até hoje com muita atualidade.

Na obra de Emília Ferreiro, concebe-se com muito ineditismo os processos mentais pelos quais a criança passa para adquirir o conhecimento da escrita, no entanto, escolhe-se uma concepção linear, descritiva de etapas que se sucedem regularmente. Para o professor, a proposta é uma base de diagnóstico do desen-

4 Programa de formação continuada oferecido pelo governo federal (Ministério da Educação - MEC) a professores alfabetizadores em várias edições, os municípios aderiam se fosse-lhes oportuno.

5 Seguiu-se ao Pro-Letramento a edição do Programa Nacional de Alfabetização na Idade certa, Pnaic, desde 2013, até o momento atual. 
volvimento infantil que oferece parâmetros bem delimitados, sequencialmente previstos. Além do trabalho incontornável e atual de Smolka, outras críticas ainda serão feitas a esta lineridade, com muito vigor e sempre apresentando propostas de formas mais ricas de abordagem didática da língua escrita pelos professores.

O livro Cenas de Aquisição da escrita é uma fonte importante que formula tais críticas, escrito alguns anos mais tarde pelo trio de autoras do Instituto de Estudos da Linguagem da Unicamp (ABAURRE; FIAD; MAYRINK-SABINSON, 1997). Neste, a singularidade dos processos infantis é abordada enfaticamente, através da demonstração feita por inúmeros exemplos retirados do banco de dados de pesquisa, de crianças de diversos pontos do Brasil, escrevendo em idade escolar. A crítica à abordagem piagetiana também é feita de forma muito esclarecedora, revelando que há muitos aspectos da escrita infantil que escapam a quem se atém estritamente às descrições de Ferreiro. O etapismo, por exemplo, ou seja, a compreensão dos processos dos aprendizes pela ideia de sequência, de pré-requisitos, é criticado, demonstrando-se com abundante conjunto de dados, de textos infantis, que há mais idas e vindas nesse processo do que se poderia supor com a visão construtivista. Pode-se identificar os avanços infantis através de seu movimento nada linear, em que revelam simultaneamente que avançam, mas que também hesitam e retomam hipóteses consideradas "superadas", que voltam a prevalecer.

Os trabalhos de pesquisa acumulados já são muitos, nas ondas da alfabetização, a se levantarem e descerem, entrecruzarem-se e estourarem, sempre em prol de uma abertura de horizontes dos que estão no chão da escola, os professores. As pesquisas buscam apresentar perspectivas que apontem para o singular trabalho do sujeito com a língua, exigindo uma definição do conhecimento linguístico e cognitivo do sujeito aprendiz (infantil e adulto), para além do que oferece a abertura teórica construtivista. No trecho abaixo, de um autor primordial na produção desta onda de conhecimento aqui defendida (CHACON, 2003), revela-se tal intensidade:

Trabalhos como os de Abaurre (1988, 1989, 1991, 1996 e 1999), Abaurre e Cagliari (1985), Abaurre e Silva (1993), Abaurre, Fiad \& Mayrink-Sabinson (1997), Cagliari (1993 e 1998), Silva (1994) e Capristano (2003) mostram-se, a nosso ver, como particularmente significativos no contexto brasileiro, na medida em que têm permitido a detecção de importantes fatos da relação sujeito/linguagem no processo lingüístico convencionalmente chamado de aquisição da escrita. Nosso destaque a esses trabalhos se deve, sobretudo, a vínculos que seus autores estabelecem entre fatos mais característicos da escrita (como a escolha de grafemas e as hipóteses de segmentação) e a intuição, por parte das crianças, de fatos fonético-fonológicos da língua (em sua dimensão segmental ou prosódica) (p. 35, grifos nossos). 
Entretanto, é preciso admitir que a hegemonia da abordagem discursiva não é um fato, ainda que ela esteja ao nosso alcance, floresça em nosso meio, presente dentro das possibilidades de escolhas teóricas de um professor alfabetizador brasileiro. Estes autores inscrevem-se sobretudo na área de pesquisa da Linguística Aplicada, mas têm uma interferência tímida no cenário de possibilidades teóricas a serem abordadas.

$\mathrm{Na}$ abordagem discursiva, o construtivismo e a descrição de etapas percorridas universalmente por aprendizes que ativamente interagem cognitivamente com o objeto de conhecimento da língua escrita não são descartados, lançados a um espaço de inutilidades, pela abordagem discursiva. Consideram-se as diversas formas pelas quais os aprendizes da língua escrita passam, superando diferentes formas de considerar a língua escrita, construindo hipóteses, em momentos que se sucedem. Porém os modos formais pelos quais são pensadas as diferentes etapas da língua na forma mental do aprendiz não são os únicos, há mais trabalho possível para além do que descreve a teoria em questão. A abordagem construtivista pode ser necessária, porém não se revela suficiente: ela se revela menos abrangente do que a abordagem discursiva. A temporalidade das etapas, por exemplo, mostra isso de forma clara. Os aprendizes têm idas e voltas, no mesmo momento de escrita (mesmo texto) apresentam hipóteses sobre a escrita das mesmas palavras de modo distinto, porque as formulações não se sucedem necessariamente. Há mais aspectos linguísticos a serem compreendidos do que supõe a teoria piagetiana, no que diz respeito à aquisição da escrita.

O Construtivismo estabeleceu-se definitivamente como a abordagem mais destacada e de atualidade no cenário, posando de única possibilidade, na maior parte das vezes. O "desembarque" da concepção de Letramento como fonte de inovação para se pensar a didática da língua escrita teve uma efusiva recepção, porém poucos anos depois os próprios autores que haviam defendido, divulgado e assinado teoricamente sua importância fazem mea culpa, repensam suas ideias (SOARES, 2004; GOULART, 2014). A onda do letramento como fonte de inovação para se pensar a didática da língua escrita foi muito impactante, alardeando-se no fim dos anos 1990, mas logo veio a sofrer críticas atrozes, talvez por ter falhado efetivamente por não ser ele mesmo produzido dentro do campo da educação, permaneceu com questões ligadas às práticas sociais sem se dar por compromisso elaborar as consequências pedagógicas de alguns de seus preceitos teóricos. As ideias sociológicas, de valorização das práticas sociais em torno da leitura e da escrita, capturadas a partir de uma imersão etnográfica, pareciam sofrer críticas, 
talvez por não terem vindo a prescrever, passo a passo perspectivas didáticas de forma um pouco mais enquadrada, que exemplificassem um tanto mais concretamente os modos de agir curriculares.

O método fônico, ainda que possa também ser considerado uma onda recente, não representava, entretanto, uma inovação no cenário brasileiro da alfabetização, mas ao contrário, significava um retrocesso histórico, já tendo sido considerado ultrapassado desde o tempo da querela dos métodos, substituída (como todos os métodos que eram debatidos anteriormente) pelo boom do construtivismo. Foi impulsionado mais recentemente, através de diversas iniciativas privadas e, inusitada e surpreendentemente, vem ganhando terreno e chega a criar bolsões de influência não só no ensino privado mas também no público, através da venda de materiais por fundações e instituições que se arvoram como de pesquisa, alegando um conhecimento "científico", mas isentando-se de debater com os demais, muito ao contrário, desmerecem todo o panorama da pesquisa brasileira para tentar assim se afirmar (ANDRADE, 2010; GOULART, 2016).

\section{A voz docente em escritas de professores alfabetizadores}

Temos estimulado a escrita e buscado meios de publicação dos professores alfabetizadores que se encontram conosco em processos de formação continuada. Recentemente, elaboramos um dossiê apenas com textos docentes, resultantes de nossa pesquisa (ANDRADE, 2016). Desta publicação extraímos alguns exemplos, aqui analisados. Destacaremos trechos dos textos docentes, retirados do conjunto de 11 textos de autoria de professores que relatam e refletem sobre suas práticas alfabetizadoras. Esperamos mostrar a coerência da abordagem discursiva da alfabetização, observada apenas pela voz docente, por seus modos de se expressar sobre o seu trabalho, pelas aproximações e os pontos de divergência na organização dos diferentes textos, pontos importantes que nos revelam as singularidades das alfabetizações, nas suas relações com a linguagem, com os sujeitos, sobre uma e sobre os outros.

Os textos se marcam por algumas características que revelam marcas da formação experimentada. Um primeiro aspecto a ser observado é que as professoras autoras relatam suas práticas, mas em nenhum dos textos entram diretamente no mérito deste assunto, para produzir (a seco) uma crônica de sua sala de aula. Antes, introduzem sua própria pessoa, autorizam-se como profissionais a marcar seu ponto de vista a partir de uma narrativa profissional de si, que fala de sua formação profissional, de sua experiência escolar ou do seu contato particular com a 
teoria. Em seguida, os aspectos discutidos acima sobre a consistência da abordagem discursiva surgem nos textos pela voz dos professores autores.

Lendo-se o dossiê completo, observar-se-á, certamente, a presença de um texto fonte, que agradou muito aos professores em formação, estudado, discutido e analisado no processo de formação (ANDRADE, 2011). Esta é outra característica dos textos publicados, a da diversidade da apropriação de textos-fonte. Consideramos interessante observar como as apropriações de um mesmo texto se dão de forma tão distinta, revelando uma autorização a expor sua própria visão sobre o ensino. Se todos passassem por processos semelhantes, diríamos que a formação os formatou, homogeneizando os sujeitos. A presença em diversos dos textos desta mesma fonte bibliográfica, entretanto, parece apenas jogar a favor da perspectiva discursiva.

A parceria entre alunos e professores é um ponto marcante nos discursos destes professores:

O trabalho com projetos sempre foi norteador da minha prática. No início mais tímido e a cada ano com nova turma foi ganhando peso, forma e sentido. Foi e é fundamental para o melhor desenvolvimento da leitura, da escrita, da oralidade e do crescimento dos meus alunos. Acredito que a cada ano surgem novas possibilidades e o grupo me surpreende com suas escolhas. Relato aqui, suas escolhas, porque os projetos são desenvolvidos de acordo com o interesse do grupo. Durante as primeiras semanas de aula, já converso com os alunos e vou percebendo o interesse que apresentam por variados temas.

Como professora e orientadora desse processo, também palpito, com minhas opiniões a respeito de possíveis temas de estudo e que estejam de acordo com o interesse da turma. O desenho do projeto vai desenvolvendo-se e tornando-se cada vez maior, justamente porque os alunos são instigados a participar ativamente dessa construção (WERNECK, 2016, p. 154, grifos nossos).

A abordagem da professora autora deste artigo, Simone Werneck, pode ser considerada dentro dos parâmetros discursivo-enunciativos. Para apresentar seu trabalho, emoldura-o antes. Não descreve diretamente seu trabalho, através do relato linear de uma sucessão de atividades encadeadas, mas assume a dependência máxima de elementos do contexto escolar para o sucesso de sua prática relatada. Inclui-se e inclui seus alunos como sujeitos, em constante interlocução. Deste trecho acima transcrito, destaco a ênfase em uma temporalidade própria para sua maturidade profissional ao longo dos anos letivos, expressando que a cada ano se sente outra, trabalhando com a mesma abordagem (de projetos). Em seguida, deixa claro que está atenta às escolhas dos alunos, ouve-os, para responder-lhes, e dar curso ao seu trabalho. 
Os projetos são escritos pelo professor e são lidos para a turma em seguida e todo o grupo define como será feita a culminância do mesmo. Todos os processos são sempre feitos em discussão com todo o grupo para que a participação e o envolvimento de todos, de fato, aconteça. A oralidade permeia todo esse processo de construção do projeto coletivamente e de elaboração das atividades e encaminhamentos de aprendizado dos alunos. Estamos o tempo todo discutindo e reinventando o estudo. Entendo que é complicado separar o que é estudo do que é alfabetização. Muitas vezes quando falo a respeito do trabalho com projetos para outros professores, sou indagada no seguinte sentido: em que momento entra a alfabetização? E o ba-be-bi-bo-bu? E a sistematização da leitura e da escrita? Mas na realidade esse trabalho não é separado e sim é o próprio trabalho de alfabetizar, pois dentro do projeto sistematizo a escrita, trabalho com textos de diferentes gêneros, utilizo o conhecimento do aluno, trabalho a oralidade, a produção individual e coletiva, estimulo a colaboração e a troca de experiências entre o conhecimento dos alunos e dou sentido à alfabetização. (WERNECK, 2016, p. 155, grifos nossos).

No trecho acima, além de reiterar a ideia de constante ressignificação das práticas propostas aos alunos, na temporalidade da profissão já apontada acima, vemos também a imbricação dos usos da linguagem propostos que são identificados e conscientes pela professora (“A oralidade permeia todo o processo...”). A alfabetização se dá pelos diferentes usos da linguagem verbal propostos, conforme ela descreve, melhor do que eu poderia parafrasear.

A ideia de que o professor, ao escutar as crianças, pode ler o seu próprio trabalho, ler-se a si mesmo, é expressa em vários momentos. Destacamos o trecho abaixo, por considerar exemplar o modo como a professora Giselle Amorim (2016) a explica:

Se eu digo que meu aluno tem dificuldades com a leitura e com a interpretação de textos, ou que não consegue escrever uma redação, eu também devo me perguntar: Enquanto professora, estou trabalhando leituras das mais variadas em sala de aula? Proporciono atividades de escrita e reescrita em sala de aula? Trabalho com a oralidade, ouvindo, respondendo e articulando com a turma os assuntos abordados que surgem no espaço da sala de aula? Ofereço atividades variadas onde ele possa se expressar? Ou simplesmente sigo um manual que já está posto no imaginário da escola, que é seguido, como uma rotina mecânica de atividades que faço, sem me inserir nesse espaço, como uma professora pesquisadora que sabe a sua função social e política no espaço da escola? Tenho feito nos vários momentos que estou no efetivo exercício da docência com os meus alunos da sala de aula ou em qualquer outro espaço de aprendizagem essas reflexões, que me ajudam a desenvolver o meu trabalho com autonomia (p. 87, grifos do autor).

A professora Elaine Lourenço Cordeiro (2016), em seu artigo, faz uma interessante e rica análise dos textos de seus alunos, contextualizando diversos momentos da produção de gêneros discursivos variados, tomando grupos de alu- 
nos que se identificaram por produzir estilos ("românticos", por exemplo), por utilizarem-se da ocasião para comunicarem certos propósitos enunciativos (advertências aos pais, por exemplo), situando por vezes apenas um caso de um aluno que considera relevante, saliente. Chama-nos atenção sua análise pelo prazer de elencar as variedades, abrir-se à leitura do que as crianças produzem identificando sentidos novos, atribuídos por eles, que lhe surpreende. Ela nos levou a incorporar a abordagem de pesquisa do linguista Lourenço Chacon (2003) que, para tratar de aspectos linguísticos em um conjunto de textos de crianças também elaborados em contexto escolar, distingue, para produzir a pretendida análise discursiva, os seguintes aspectos:

a) variação inter-sujeitos;

b) variação intra-sujeitos;

c) variação em função de tipos de textos;

d) aumento de marcas de pontuação ao longo do ano;

e) saliência do caráter gráfico da pontuação nas primeiras produções textuais;

f) percepção de conjunção não-isomórfica de elementos de várias naturezas linguísticas nas estruturas delimitadas por sinais de pontuação ( p. 40).

Remeto o leitor ao referido dossiê, fonte da empiria apresentada, observando como o que define a abordagem discursiva é a relação que professores têm com a linguagem, que inclui de forma radicalmente saliente os estilos infantis: suas formas de conceber o ensino a se produzir, suas possibilidades de expressão sobre o ensino, sobre a língua e sobre si mesmos. Professores com esse estilo autorizam-se coerentemente a dar voz a seus alunos, de modo que as alteridades dentro dos processos escolares vão se construindo, se interconstituindo, de acordo com uma perspectiva discursiva sobre as produções escolares.

\section{Referências}

ABAURRE, M. B. M.; FIAD, R. S.; MAYRINK-SABINSON, M. L. T. Cenas de aquisição da escrita: o sujeito e o trabalho com o texto. Campinas, SP: ALB, Mercado de Letras, 1997.

AMORIM, G. Uma experiência de reescrita na alfabetização. Revista Práticas de Linguagem, Juiz de Fora, v. 5, n. 2, p. 77-90, jul./dez. 2016.

ANDRADE, L. T. de. O professor alfabetizador imantado entre propostas teóricas: o letramento e a metodologia do fônico. In: SEMINÁRIO INTERNACIONAL SOBRE HISTÓRIA DO ENSINO DE LEITURA E ESCRITA, 1., 2010, Marília. Anais...Marília: SIHELE, 2010. 
ANDRADE, L. T. de. Novos espaços discursivos na escola, formadores de novos leitores, de uma nova língua escrita. Revista Pátio, v. 59, p. 14-17, 2011.

. Entre fazer e dizer: atividade docente e práticas pedagógicas escolares, nos atos de escrita na formação. Raído, Dourados, v. 8, n. 16, jul./dez. 2014a.

As possíveis alfabetizações pela visão dos docentes. In: SEMINÁRIO ESCRITA DOCENTE E DISCENTE, 3., 2014, Rio de Janeiro. Anais... Rio de Janeiro, 2014b.

de. Encontros de professores para estudos de letramento, leitura e escrita: a autoria de textos docentes. Revista Práticas de Linguagem, Juiz de Fora, v. 5, n. 2, p. 6-15, jul./dez. 2016.

ARENA, D. B. As letras como unidades históricas na construção do discurso. Cadernos CEDES, Campinas, v. 33, n. 89, p. 109-123, jan./abr. 2013.

BAKHTIN, M. Marxismo e Filosofia da Linguagem. São Paulo HUCITEC, 1988.

. Estética da criação verbal. São Paulo: Martins Fontes, 2003.

. Questões de estilística no ensino da língua. São Paulo: Editora 34, 2013.

BALL, S. J. Reformar escolas/reformar professores e os terrores da performatividade. Revista Portuguesa de Educação, Braga, v. 15, n. 2, p. 3-23, 2002.

BATISTA, A. A. G. Professoras de Português, formação superior, matrimônio e leitura: um caso de estudo. In: PAIXÃO, L. P.; ZAGO, N. (Org.). Sociologia da Educação: pesquisa e realidade brasileira. Petrópolis: Vozes, 2007.

BORÉ, C.; BOSREDON, C. La phrase selon les brouillons: un trajet entre l'oral et l'écrit. Le français aujourd'hui, n. 181, p. 13-24, 2013.

CARVAlHO, M. A. de O. Alfabetizar e letrar: um diálogo entre a teoria e a prática. 7a. ed. Petrópolis: Vozes, 2010. v. 1.

CHACON, L. Oralidade e letramento na construção da pontuação. In: ENCONTRO DO CELSUL. 5., 2003, Curitiba. Anais... Curitiba: Fundação Araucária, 2002.

CORDEIRO, E. L. da S. Relato e reflexões sobre o cotidiano escolar em turma de $2^{\circ}$ ano com enfoque na produção de textos: escritores iniciantes produtores de textos Uma experiência de reescrita na alfabetização. Revista Práticas de Linguagem, Juiz de Fora, v. 5 n. 2, p. 113-153, 2016.

CORREA, M. L. G. O modo heterogêneo de constituição da escrita. São Paulo: Martins Fontes, 2004.

COSTA, P. A. Letramentos familiares de crianças de classe popular: alfabetizações possíveis. 2013. 58 p. Monografia (Graduação em Pedagogia) - Faculdade de Educação, Universidade Federal do Rio de Janeiro, Rio de Janeiro, 2013. 
DOQUET-LACOSTE, C. Écrits intermédiaires, écritures intermitentes: carnets, notes, bribes de science. Langage et société, n. 127, 7-22, 2009.

FERREIRO, E.; TEBEROSKY, A. Psicogênese da língua escrita. Tradução: Diana Myriam Lichtenstein et al. Porto Alegre: Artes Médicas, 1986.

FOUCAULT, M. Lordre du discours. Paris: Gallimard, 1971.

ORGANIZAÇÃO DAS NAÇÕES UNIDAS PARA A EDUCAÇÃO, A CIÊNCIA E A CULTURA. O perfil dos professores brasileiros: o que fazem, o que pensam, o que almejam - Pesquisa Nacional Unesco. São Paulo: Moderna, 2004.

GOULART, C. M. A. O conceito de letramento em questão: por uma perspectiva discursiva da alfabetização. Bakhtiniana [online], São Paulo, v.9, n.2, pp. 35-51, jul./dez. 2014. doi: http:// dx.doi.org/10.1590/S2176-45732014000200004

GOULART, C. Carta de Cecília Goulart (UFF) em resposta a artigo de presidente do Instituto Alfa e Beto no jornal Estadão [on-line]. 2016. Disponível em: <http://www.anped.org.br/news/ carta-de-cecilia-goulart-uff-em-resposta-artigo-de-presidente-do-instituto-alfa-e-beto-no $>$. Acesso em: 04 dez. 2017.

KLEIMAN, Â. B. Os significados do letramento: uma nova perspectiva sobre a prática social da escrita. Campinas: Mercado de Letras, 1995.

LUCIO, E. O. Tecendo os fios da rede: o programa pró-letramento e a tutoria da formação continuada de professores alfabetizadores da educação básica. 2010. 299 f., Dissertação (Mestrado em Educação.) - Faculdade de Educação, Universidade Federal do Rio de Janeiro, Rio de Janeiro, 2010.

LUCIO, E. O. A palavra conta, o discurso desvela: saberes docentes na formação continuada de professores de leitura e escrita. 2016. 300 f. Tese (Doutorado em Educação) - Faculdade de Educação, Universidade Federal do Rio de Janeiro, Rio de Janeiro, 2016.

MAINGUENEAU, D. Novas tendências em Análise do Discurso. Campinas, SP: Pontes, 1997.

MARINHO, M.; CARVALHO, G. T. (Org.). Cultura escrita e letramento. Belo Horizonte: Editora da UFMG, 2010.

MORTATI, M. do R. Letrar é preciso, alfabetizar não basta... mais?. In: SCHOLZE, L.; ROSING, M. K. (Org.). Teorias e práticas de letramento. Brasília, DF: INEP, 2007. p. 155-168.

SIROTA, R. Emergência de uma sociologia da infância: evolução do objeto e do olhar. Cadernos de Pesquisa, São Paulo, n. 112, p. 7-31, mar. 2001.

SMOLKA, A. L. B. A criança na fase inicial da escrita: a alfabetização como processo discursivo. São Paulo: Cortez, 1988. 
SOARES, M. Letramento: um tema em três gêneros. Belo Horizonte: Autêntica, 1998.

SOARES, M. B. Letramento e alfabetização: as muitas facetas. Revista Brasileira de Educação, n. 25, p. 5-17., 2004. doi: http://dx.doi.org/10.1590/S1413-24782004000100002

STREET, B. V. Os novos estudos sobre o letramento: Histórico e perspectivas. In: MARINHO, M.; CARVALHO, G. T. (Org.). Cultura escrita e letramento. Belo Horizonte: Editora da UFMG, 2010. p. 33-53.

THIN, D. Para uma análise das relações entre famílias para uma análise das relações entre famílias populares e escola: confrontação entre lógicas populares e escola: confrontação entre lógicas socializadoras. Revista Brasileira de Educação, Rio de Janeiro, v. 11, n. 32, p. 211-225, maio/ago. 2006.

WERNECK, S. Alfabetizar ou elaborar projetos? Revista Práticas de Linguagem, Juiz de Fora, v. 5, n. 2, 154-160, jul./dez. 2016.

Submissão em: 31-10-2017

Aprovação em: 01-11-2017 